\title{
Investigating the relation between emotional intelligence and mental health of the students majoring in educational sciences in the year 2012 at the Mahabad's Payame Noor University
}

\author{
Heman Mahmoudfakhe*, Morad Abdivarmazan, Toba Amini \\ Department of Psychology, Payame Noor University, PO BOX 19395 - 3697, Tehran, Iran \\ *E-mail address: hemanpsycho@yahoo.com
}

\begin{abstract}
The current research was carried out with the aim of investigating the relation between the emotional intelligence and mental health of the students majoring in educational sciences in the year 2012 at the Mahabad Payame Noor University. For this purpose, we chose 86 students from among 150 students through simple random sampling and these 86 people responded to the questionnaire of emotional intelligence and mental health. After analyzing the findings, we concluded that there is a significant relation between the emotional intelligence and mental health of these students and the correlation is positive. The average scores pertaining to physical symptoms, anxiety, disorders in social performance and depression are respectively 13/372, 13/767, 8/418 and 15/569.
\end{abstract}

Keywords: Mental health; Emotional intelligence; educational sciences

\section{INTRODUCTION}

The emotional intelligence is a topic that attempts to explain and interprets the man excitement, feeling and capability status (Hasanzadeh, 2007). The emotional intelligence has been defined as an ability to understand and comprehend the emotions in order for assessing thoughts, manners and to put them in a way that makes emotion and intelligent growth and elevation (Golman, 1995). The concept of emotional intelligence gives a new depth to the man's intelligence, this intelligence is a tactical competency (personal performance), whilst the recognition intelligence is a strategic capability (long term capability). The emotional intelligence makes it possible to predict the achievement because it demonstrates how a person apply a knowledge in an immediately success. It is a form of social intelligence which is a suitable predictor in special areas such as job and educational performances. In the other word, it has an ability to control feelings and excitements by oneself and others (Bar-on, 2000).

Intelligence Quotient (IQ) in its best form causes only 20 percent of life successes and all 80 percent remaining depends on another factor and the human's fate in the most cases depends on the skills that link to the emotional intelligence to provide person adaptability with the environment and is a better predictor of success in university, work and home than the analytic intelligence. (Mayer \& Salovi 1997). The other factor which is effective in academic 
advancement is self-esteem. It is personal self-satisfaction and his sense of being valuable (Bandura \& Adams, 1977). Mental health is one of the important aspects of health. According to the World Health Organization definition, mental health includes the ability to establish harmonious relationship with others, improving personal and social environment and resolving conflicts and personal desires in a logical, fair and appropriate manner (Abbasi et al, 2001). The term mental health is a very broad concept and includes mental wellbeing, the sense of empowerment, adequacy, understanding of intergenerational solidarity and the ability to recognize the intellectual and emotional potential in a person, in such a way that the person can recognize his/her abilities and cope with the stresses of the routine life and be productive and efficient in terms of his/her job (Emamhadi et al, 2006). Vitality, joy, feeling of happiness is one of the divine gifts, bestowed on mankind in the light of well being and mental health; furthermore, mental health is one of the effective factors in promotion and development of people (Yoosefi et al, 2010).

Mental health is the ability to communicate harmoniously and coordinately with others, change and modify the personal and social settings, and solve conflicts and personal inclinations justly, rationally and appropriately. The term "mental health" is unfortunately used with little ambiguity and it is usually mistaken, because people consider it a ' mere desire of people who have mental disorders and complaints and could be treated by making the use of psychotherapists. In this sense, "health" stands against: physical health " and it is imagined that mental health is distinct from the physical health, while both these impressions are wrong By mental or rational health, it is meant some activities carried out for helping suffering people so that these people are saved from their problems and also, they are guided in preventing predicaments and miseries. Thus, mental health never ignores the quality of the humans ' physical health.

"Realize yourself ", the Socrates is based on the principle of the emotional intelligence, i.e. awareness towards one's feelings by the time they emerge. It is likely that in the first glimpse, it seems that our feelings are clear and evident (Bradbury \& Greeves, 2004). Emotional intelligence is the conscious choosing of thinking, feeling and act to attain the best of results in relations with self and others. Emotional intelligence is a fundamental element of the man's conduct that acts distinctly from the cognitive emotion. The emotional intelligence is a resilient skill taught simply. Although some people naturally have higher emotional intelligence than others, someone, who's born without emotional intelligence could also create in himself higher emotional and affection intelligence (Bradbury \& Greeves, 2004). Any problem in its life span becomes ready to be solved and destroyed. Emotions are means whereby we can proceed to solve our problems, a problem so big that you can see it while it is so small that you can solve it and you can escape these problems intelligently by understanding one's emotions and also you can avoid later problems. Emotional intelligence skills could enable us to avoid tricky situations before they become uncontrollable (Hajloo et al, 2007). Advancements in industry and technology have increased power and wealth while they have divested from man the possibility of a life with comfort and peace and confidence. In fact, quality is replaced by quantity and moderation and conformity are substituted with mental and nervous diseases. Forso long, mental health has been latent behind the curtain of discrimination and segregation and today progress in science has provided a ground for an expression of mental health and treating it. On the other hand, we learn that mental, physical and social health is critical for all people so to construct a course of life for themselves. Also, promoting it is necessary in all life courses. However, in some periods of time like puberty, adolescence, post obstetrics, pregnancy and education years, one should deal with them better (Ganji, 1998). 
Having regard to the above instances and the importance that emotional intelligence and mental health have in the life of people, the topic is addressed in this paper.

\section{RESEARCH HYPOTHESES}

a) There is a relation between emotional intelligence and mental health of the students majoring in educational sciences.

b) There is a relation between emotional intelligence and depression of the students majoring in educational sciences.

c) There is a relation between emotional intelligence and physical symptoms of the students majoring in educational sciences.

d) There is a relation between emotional intelligence and disorder with the social performance of the students majoring in educational sciences.

e) There is a relation between emotional intelligence and anxiety of the students majoring in educational sciences.

\section{METHODOLOGY}

The research type is a context - based one and we use a correlation method because we aim to measure the relation between the emotional intelligence and mental health to find out whether there is a relation between these two. For this purpose, we chose 86 students from among 150 students of the Mahabad PNU through simple random sampling and these 86 people responded to the questionnaire of emotional intelligence and mental health. After analyzing the findings, we concluded that there is a significant relation between the emotional intelligence and mental health of these students and the correlation is positive. Having regard, two variables of emotional intelligence and mental health are used in this paper and the means to collect data are Bar-on emotional intelligence questionnaire and that of Goldberg's and Hillier's.

General Health Questionnaire (GHQ) was designed in 1972 by Goldberg; This test contains 28 questions including four scales; physical complaints, anxiety, social performance, and depression (Goldberg, 1978). The simple method of Likert (0-1-2-3) was used for scoring. The cut-off point for screening was considered 23 in this test. It means that the subjects, whose scores were less than 23, were not diagnosed as patients (Hemayattalab et al, 2003). Reliability of the questionnaire reported $81 \%$ in different researches (Seyedahmadi et al, 2010).

Bar-on emotional intelligence questionnaire: In 1980, for the first time the Bar-on the emotional intelligence questionnaire was developed. It contained 133 questions which is the first super cultural questionnaire to evaluate the emotional intelligence. In 1997, this questionnaire had been reviewed and it's questions reduced to 177 ones. This review was conducted by an author on 3831 person from 6 different countries and it was customized in the North America. Responses were studied by factorial analysis and finally a general scale for (IQ) and 5 combinational scales and 15 minor scales were determined. In 1382, this test has been implemented in Iran among Tehran university students by Dehshiri (2006), and its questions were declined to 90 ones. In this research, Dehshiri has applied the revaluation method and Kronbakh Alphabet. The questionnaire's answering sheets are regulated based on a scale of 5 degree in likers spectrum as follow (I am agree completely, I'm agree, to some 
extent, I'm disagree, I'm disagree completely). For the final measurement two methods were used. Revaluation sustainability or time stability coefficients were reported respectively as $85 \%$ one month later and $75 \% 4$ month later. Test stability rate in odd-even method was $88 \%$ and in kronbakh alphabet was $93 \%$ (Samari and Tahmasbi, 2007).

We applied descriptive and inferential statistics in this paper. To describe data, the descriptive statistics was used that includes scatterdness charts between emotional intelligence and mental health. The inferential statistics was also employed to test the research hypotheses that involve a correlation coefficient test between the emotional intelligence and mental health.

\section{FINDINGS}

After the questionnaires were filled in by 86 students at the Mahabad's PNU, coded data were entered into a computer and using the SPSS11/5, the following results were obtained. For the hypotheses, the descriptive statistics (mean and standard deviation) and the Pearson $\mathrm{R}$ correlation coefficient was applied.

Table 1. Of descriptive statistics of emotional intelligence and mental health.

\begin{tabular}{|c|c|c|c|}
\hline Variables & Mean & Standard deviation & No. \\
\hline Emotional intelligence & $327 / 662$ & $15 / 265$ & 86 \\
\hline Mental health & $50 / 941$ & $9 / 759$ & 86 \\
\hline
\end{tabular}

Table (1) indicate that the average emotional intelligence scores were obtained from the emotional intelligence questionnaire and mental health scores were prepared from the mental health questionnaire and they are respectively: 327/662, 50/941.

Table 2. Of descriptive statistics of mental health components.

\begin{tabular}{|c|c|c|c|}
\hline Variables & Mean & Standard deviation & No. \\
\hline Physical signs & $13 / 372$ & $3 / 221$ & 86 \\
\hline Anxiety & $13 / 767$ & $4 / 109$ & 86 \\
\hline Performance disorder & $8 / 418$ & $3 / 721$ & 86 \\
\hline Depression & $15 / 569$ & $5 / 252$ & 86 \\
\hline
\end{tabular}

Table (2) indicate that the average scores of physical signs, anxiety and performance disorder and depression are obtained from the mental health questionnaire which are: $13 / 372,13 / 767,8 / 418$ and 15/569. 
Table 3. A correlation analysis between the emotional intelligence and mental health.

\begin{tabular}{|l|c|c|}
\hline \multirow{2}{*}{$\begin{array}{l}\text { Dependent } \\
\text { Variable }\end{array}$} & \multicolumn{2}{|c|}{ Emotional intelligence } \\
\hline \multirow{2}{*}{ Mental health } & Correlation coefficient & $0 / 357$ \\
\cline { 2 - 3 } & Sig. & $0 / 01$ \\
\cline { 2 - 3 } & Freedom degree & 85 \\
\hline
\end{tabular}

Having regard, both variables are in distance scales, we used the Pearson correlation test for testing the relation between the emotional intelligence and mental health of the students at the Mahabad's PNU where obtained results are indicative of the fact that there is a significant relationship between the mentioned variables at the level(sig. $=/ 01)$. This means a positive effect of emotional intelligence on the students' mental health.

Table 4. Correlation analysis between emotional intelligence and physical sign.

\begin{tabular}{|l|c|c|}
\hline \multirow{2}{*}{$\begin{array}{l}\text { Dependent } \\
\text { Variable }\end{array}$} & \multicolumn{2}{|c|}{ Emotional intelligence } \\
\hline \multirow{2}{*}{ Physical signs } & Correlation coefficient & $0 / 355$ \\
\cline { 2 - 3 } & Sig. & $0 / 01$ \\
\cline { 2 - 3 } & Freedom degree & 85 \\
\hline
\end{tabular}

Results suggest that there is a significant relationship between emotional intelligence and physical signs of the students at the PNU at the level (sig. =/01). This is indicative of the positive impacts of emotional intelligence on the physical signs as a component of the students' mental health.

Table 5. Correlation analysis between the students' emotional intelligence anxiety.

\begin{tabular}{|l|c|c|}
\hline \multirow{3}{*}{$\begin{array}{l}\text { Dependent } \\
\text { Variable }\end{array}$} & \multicolumn{2}{|c|}{ Emotional intelligence } \\
\hline \multirow{2}{*}{ Anxiety } & Correlation coefficient & $0 / 283$ \\
\cline { 2 - 3 } & Sig. & $0 / 01$ \\
\cline { 2 - 3 } & Freedom degree & 85 \\
\hline
\end{tabular}

Results reveal that there is a significant relationship between the students; emotional intelligence and anxiety at the significance level of $/ 01$. This means the effect of emotional intelligence on anxiety as a component of the metal heath. 
Table 6. Correlation analysis between the students' emotional intelligence and disrupted social performance.

\begin{tabular}{|c|c|c|}
\hline \multirow{2}{*}{$\begin{array}{l}\text { Dependent } \\
\text { Variable }\end{array}$} & \multicolumn{2}{|c|}{ Emotependent variable } \\
\hline \multirow{2}{*}{ Disrupted social performance } & Correlation coefficient & $-0 / 001$ \\
\cline { 2 - 3 } & Sig. & $0 / 993$ \\
\cline { 2 - 3 } & Freedom degree & 85 \\
\hline
\end{tabular}

Results indicated that there is no significant relationship between the emotional intelligence and disorders in the social performance among the students at the significance level of /993. Because, the significance level obtained is greater than $/ 05$, an absence of relation between the emotional intelligence and disorder in the social performance is concluded as a component of the mental health.

Table 7. Correlation analysis between emotional intelligence and depression.

\begin{tabular}{|c|c|c|}
\hline \multirow{3}{*}{$\begin{array}{l}\text { Dependent } \\
\text { Variable }\end{array}$} & \multicolumn{2}{|c|}{ Independent variable } \\
\hline \multirow{3}{*}{ Depression } & Correlation coefficient & 1270 \\
\cline { 2 - 3 } & Sig. & 105 \\
\cline { 2 - 3 } & Freedom degree & 85 \\
\hline
\end{tabular}

Results indicated that there is a significant relationship between the emotional intelligence and depression among the PNU students at the significance level of /05 where this suggests an effect of the emotional intelligence on depression.

\section{CONCLUSIONS}

First hypothesis: There is a relation between the students' emotional intelligence and mental health. Having regard, both variables are in distance scales, we used the Pearson correlation test for testing the relation between the emotional intelligence and mental health of the students at the Mahabad's PNU where obtained results are indicative of the fact that there is a significant relationship between the mentioned variables. This means a positive effect of emotional intelligence on the students' mental health.

Second hypothesis: There is a relation between the students' emotional intelligence and physical signs. Results suggest that there is a significant relationship between emotional intelligence and physical signs of the students. This is indicative of the positive impacts of emotional intelligence on the physical signs as a component of the students' mental health (Aghayar \& Sharifidaramad, 2006). 
Third hypothesis: There is a relation between the emotional intelligence and anxiety among the students. Results reveal that there is a significant relationship between the students' emotional intelligence and anxiety. This means the effect of emotional intelligence on anxiety as a component of the metal heath.

Fourth hypothesis: There is a relation between the emotional intelligence and disrupted social performance in the students. Results indicated that there is no significant relationship between the emotional intelligence and disorders in the social performance among the students. Because, the significance level obtained is greater than $0 / 05$, an absence of relation between the emotional intelligence and disorder in the social performance is concluded as a component of the mental health. Thus the correlation is negative.

\section{References}

[1] Abbasi A., PanahAnbari A., Kamkar A., Bagheri Zade Gh., Journal of Medicine and purification 4 (2001) 34-38.

[2] Aghayar S., Sharifidaramadi P. (2006). Emotional intelligence, Sepahan Publications.

[3] Bandura A., Adams N. E., Cognitive Therapy \& Research 1(4) (1977) 287-310.

[4] Baron R. (2000). The Handbook of Emotional Intelligence; To Ssey-Bass, While Company, San Francisco.

[5] Bradbury T., Greeves J. (2004). Emotional intelligence, skills and tests, trans. By Ganji, Savalan publications.

[6] Dehshiri Gh., Counseling Research and Recents 5(18) (2006) 97-108.

[7] Emamhadi M. A., Jalilvand M., Salehi M., Journal of Social Welfare 5(20) (2006) 153162.

[8] Ganji, H. (1998). Mental health. Arasbaran publications.

[9] Goldberg, DP. (1978). Manual of the General Health Questionnaire. Windsor, England: NFER Publishing.

[10] Goleman D. (1995). Emotional Intelligences: The Theory in Practice; Newyourk: Basic Book.

[11] Hajloo, M. (2007). Emotional intelligence, Ghaside publications.

[12] Hassan Zadeh R. (2007). The motivation and excitement. Tehran: Arasbaran Publication.

[13] Hemayattalab R., Bazazan S., Lahmi R. (2003). Comparison of Happiness and Mental Health of Female Athletes and Non-athletes Students of Payam Noor and Tehran Universities Harkate Zemestani (Winter Activities) (18): 131-140.

[14] Mayer J. D., Salovey P. (1997). What is emotion intelligence? In: Salovey P, Sluyter DJ, editors. Emotional development and emotional intelligence: Educational implications. New York: Basic Books: 3-31.

[15] Samari A. A., Tahmasbi F., The Quarterly Journal of Fundamentals of Mental Health 9(35) (2007) 121-128.

[16] Seyedahmadi M., Keivanloo F., Kushan M., Mohamadi Raouf M., Journal of Medical Sciences and Health Services of Sabzevar 17(2) (2010) 116-122. 
[17] Yousefi A., Baratali M., Erfan A., Iranian Journal of Education in Medical Sciences 10(5) (2010) 748-754.

[18] Mohamad Khaledian, Zahra Ahmadimehr, Elham Naseri, Fakhralsadat Khosravani, Mojgan Shoshtsri, International Letters of Social and Humanistic Sciences 8 (2013) 43-48.

[19] Morteza Amani, Mahmood Goodarzi, Hamze Ahamadian, International Letters of Social and Humanistic Sciences 1 (2014) 7-13.

[20] Hamid Maleki, International Letters of Social and Humanistic Sciences 7 (2014) 62-66.

[21] Naveed Ahmed, Omer Farooq, Junaid Iqbal, International Letters of Social and Humanistic Sciences 9 (2014) 1-13.

[22] Mohamad Khaledian, Majid Omidi, Mandana Sepanta, Mehdi Tavana, International Letters of Social and Humanistic Sciences 9 (2014) 108-114.

[23] Sakineh Ghayazi, Faranak Omidian, Mohammed Hosseinpoor, International Letters of Social and Humanistic Sciences 10(1) (2014) 51-61.

[24] Gholamreza Jandaghi, Hamid Reza Irani, Ehssan Jandaghi, Zeinab Sadat Mousavi, Maryam Davoodavabi, International Letters of Social and Humanistic Sciences 15(1) (2014) 78-83. 